\title{
Risk factors for injuries associated with damage claims following groin hernia repair
}

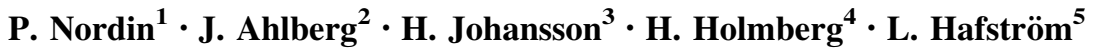

Received: 16 January 2016/ Accepted: 19 January 2017/Published online: 8 February 2017

(c) The Author(s) 2017. This article is published with open access at Springerlink.com

\begin{abstract}
Purpose Surgical repair of groin hernia should be carried out with minimal complication rates, and it is important to have regular quality control and accurate means of assessment. The Swedish healthcare system has a mutual insurance company (LÖF) that receives claims from patients who have suffered healthcare-related damage or malpractice. The Swedish Hernia Register (SHR) currently covers around $98 \%$ of all Swedish groin hernia operations. The aim of this study was to analyse damage claims following groin hernia repair surgery and link these with entries in the SHR, in order to identify risk factors and causes of injuries and malpractice associated with hernia repair.

Methods Data on all 48,574 groin hernia operations registered in the SHR between 2008 and 2010 were compared and linked with data on claims made to the Swedish National Patient Injury Insurance (LÖF).
\end{abstract}

P. Nordin

par.nordin@ regionjh.se

1 Department of Surgical and Perioperative Sciences, Umeå University, Swedish Hernia Register, Östersund, 90185 Umeå, Sweden

2 Swedish National Patient Insurance Company; LÖF, Stockholm, Sweden

3 Department of Surgical Sciences, University Hospital, Uppsala and the Swedish Patient Claims Panel, Stockholm, Sweden

4 Department of Public Health and Clinical Medicine, Umeå University, Umeå, Sweden

5 Transplant Institute, Sahlgrenska Academy at University of Gothenburg, Sahlgrenska University Hospital, Sweden and the Swedish Patient Claims Panel, Gothenburg, Stockholm, Sweden
Results Of the 130 damage claims received by LÖF, 26 dealt with bleeding, 20 with testicular injury and 7 with intestinal lesions. Eighty (62\%) of the complications were considered malpractice according to the Swedish Patient Injury Act. Acute and recurrent surgery, sutured repair and general anaesthesia were associated with a significantly increased risk for a damage claim independently the patients were compensated or not. Females filed claims in greater proportion than males. There was no significant difference in background factors between claims accepted by LÖF and compensated and those who were rejected compensation.

Conclusion Risk factors for filing a damage claim included acute surgery, operation for recurrence, sutured repair and general anaesthesia, whereas local anaesthesia reduced the risk.

Keywords Groin hernia repair · Damage claims . Malpractice

\section{Introduction}

In Sweden, about 16,000 groin hernia repairs are performed annually. The Swedish Hernia Register (SHR) has been in existence since 1992. Today, practically all Swedish surgical centres register hernia repairs with the SHR, giving a present coverage of $98 \%$. Registration of data is made by healthcare staff.

Since 1975, Sweden has had a patient insurance scheme offering compensation for healthcare-related injuries, mandated in the Swedish Patient Injury Act. Patients treated within the Swedish healthcare system can claim compensation for malpractice injuries from the Swedish National Patient Insurance Company; LÖF, which covers 
90-95\% of all claims made by patients treated in public financing health care. According to the law, it is only the patients or next of kin who can file a claim, and they do so independently of the treating institution, based on their own opinion of existence and cause of the injury-malpractice.

By using two different data sources, each with different strengths and weaknesses, it should be possible to increase the completeness of data, especially by identifying the injuries behind the claims.

The aims of this study were to, increase knowledge about type and frequency of injuries in hernia surgery by using data from both the SHR and from LÖF, and identify risk factors for damage claims due to injury associated with groin hernia repair.

\section{Materials and methods}

The study was performed as a retrospective cohort study. Data from the SHR were linked with data from LÖF, using the Swedish civic registration number (a unique number issued to all Swedish citizens or those with a permanent residence permit). All patients filing damage claims to LÖF following groin hernia surgery performed in 2008 through 2010 were included in the study, as were all patients entered in the SHR during the same years. Analyses were made to identify the injuries behind the claims sent to LÖF, and how they were registered in the SHR.

Primary endpoint Causes of the compensated and noncompensated claims, characteristics of injuries and risk factors behind damage claims resulting from injury associated with groin hernia repair.

Secondary endpoint Impact of gender, age, hernia anatomy, elective and acute surgery and type and frequency of injuries.

\section{Databases}

The SHR covers almost all groin hernia repairs in Sweden on patients aged 15 years and older. It includes data on surgery, type of hernia, elective or acute surgery, type of repair, form of anaesthesia, postoperative complications within 30 days and reoperation for recurrence. Today, but not during the study period, the SHR also contains data from a patient-related questionnaire regarding pain and satisfaction at one year after surgery. Five evaluators randomly visit one in ten of the participating units each year, and check the validity of data registered in the SHR, as well as checking for operations not registered [1].

LÖF receives 15,000 claims each year from patients injured in Swedish health- and dental care. LÖF insures around $95 \%$ of all health- and dental care. If the injury is considered as malpractice or avoidable according to the
Swedish Patient Injury Act, the patients are entitled to compensation for pain and suffering, and any financial losses caused by the damage. The criteria for being avoidable is if an experienced specialist in the same field of practice could have chosen another treatment or procedure or performed the procedure in some other way and by doing so avoiding the injury. This assessment is made by experienced medical advisors. If they consider the injury to be avoidable by more than $50 \%$ the claimant will be compensated. All claims received are stored in a claims database, today covering over 150,000 entries.

\section{Inclusion criteria}

All patients, 15 years of age or older, who underwent groin hernia repair in Sweden during 2008 through 2010 were collected from the SHR. From the same years, all patients that had filed a claims for malpractice to LÖF related to hernia surgery were analysed.

\section{Statistics}

Chi-square test was used for all categorical variables. Odds ratios (OR) with $95 \%$ confidence intervals $(\mathrm{CI})$ were calculated from the sample proportions.

\section{Ethics}

The study protocol was approved by the Regional Ethics Committee of Umeå University.

\section{Results}

In 2008 through 2010, 48574 patients subjected to hernia repair surgery, either inguinal $(n=46687)$ or femoral ( $n=1427)$, were registered in the SHR. Until May 2015 LÖF received, 130 claims for compensation for injuries after hernia surgery performed during the same period corresponding to $0.27 \%$ of the total material.

The characteristics of the SHR and LÖF data are shown in Table 1. The $p$ values given show the relative difference between the SHR and the LÖF figures. The male/female ratio in the SHR during the study period was 10.9:1 (44 461/4 113) and in the LÖF database 6.6:1 (113/17). The median age in the SHR material was 61 years, and in the LÖF database 58 .

Patients who underwent repair for recurrent hernia, acute surgery, open sutured repair, and general anaesthesia were more common in the LÖF register than in the SHR.

The damage claims received by LÖF and those that received compensation are shown in Table 2 . The most frequent claim was haematoma/bleeding $(n=26)$, and 19 
Table 1 Patient characteristics in the Swedish Hernia Register and in the claim database from the Swedish National Patient Injury Insurance (LÖF)

\begin{tabular}{|c|c|c|c|}
\hline & SHR & LÖF & $p$ value* \\
\hline \multicolumn{4}{|l|}{ Gender } \\
\hline Male $(\%)$ & $44,461(92)$ & $113(87)$ & 0.08 \\
\hline Female $(\%)$ & $4113(8)$ & $17(13)$ & 0.08 \\
\hline Total & 48,574 & 130 & \\
\hline \multicolumn{4}{|l|}{ Age } \\
\hline Median, years & 61 & 58 & \\
\hline \multicolumn{4}{|l|}{ Hernia anatomy } \\
\hline Inguinal (\%) & $46,687(96)$ & $127(98)$ & 0.48 \\
\hline Femoral $(\%)$ & $1427(3)$ & $3(2)$ & 0.87 \\
\hline Not stated $(\%)$ & $460(1)$ & & \\
\hline Total & 48,574 & 130 & \\
\hline \multicolumn{4}{|l|}{ Type of hernia } \\
\hline Primary $(\%)$ & $44,169(90)$ & $110(85)$ & 0.02 \\
\hline Recurrent (\%) & $4405(10)$ & $20(15)$ & 0.02 \\
\hline Unilateral (\%) & 43,999 (91) & $119(92)$ & 0.82 \\
\hline Bilateral (\%) & $4575(9)$ & $10(8)$ & 0.60 \\
\hline Sliding hernia (\%) & $4675(9)$ & $8(6)$ & 0.23 \\
\hline \multicolumn{4}{|l|}{ Type of operation } \\
\hline Elective $(\%)$ & $46,048(95)$ & $117(90)$ & 0.02 \\
\hline Acute $(\%)$ & $2526(5)$ & $13(10)$ & 0.02 \\
\hline Total & 48,574 & 130 & \\
\hline \multicolumn{4}{|l|}{ Hernia repair } \\
\hline Open sutured repair $(\%)$ & $2058(4)$ & $13(10)$ & 0.002 \\
\hline Laparoscopic (\%) & $5706(12)$ & $15(12)$ & 1 \\
\hline Open mesh repair $(\%)$ & $40,694(84)$ & $100(77)$ & 0.046 \\
\hline Not stated $(\%)$ & $116(0)$ & $2(2)$ & \\
\hline Total & 48,574 & 130 & \\
\hline \multicolumn{4}{|l|}{ Type of anaesthesia } \\
\hline General anaesthesia (\%) & $35,138(72)$ & $107(82)$ & 0.015 \\
\hline Local (\%) & $9722(20)$ & $10(8)$ & 0.0007 \\
\hline Epidural or spinal (\%) & $3709(8)$ & $11(8)$ & 0.85 \\
\hline Not stated $(\%)$ & $5(0)$ & $2(2)$ & \\
\hline Total & 48,574 & 130 & \\
\hline
\end{tabular}

All operations done between January 1, 2008 and December 31, 2010

* Chi-square test

of these $(73 \%)$ received compensation (Table 2). Of all 130 claimants, $80(62 \%)$ received compensation. In the noncompensated group $(n=50)$ LÖF did not consider that the complication was due to a malpractice.

Complications registered after groin hernia surgery in the SHR are shown in Table 3. They were identified during or immediately after surgery, or occurred within one month after surgery. Of the 48574 groin hernia procedures registered in the SHR, complications were registered for 3856 patients $(8 \%)$. Bleeding was the predominant adverse event; $37 \%$ of all complications.
Females had a borderline statistically significant increased risk for damage motivating the patient to make a claim compared to men $(p=0.06$; OR $1.62 ; 95 \% \mathrm{CL}$ 0.98-2.71). Analysis of risk factors for claiming damage compensation showed that acute surgery, operation for recurrence, sutured repair and general anaesthesia were associated with a significantly increased risk for a complication leading to claim. Local anaesthesia reduced the risk (Table 4). In patients who received compensation acute surgery and laparoscopic/sutured repair were significant risks for adverse effects whereas local anaesthesia reduced the risk (Table 4).

There was no difference in background factors for LÖF to consider a claim as malpractice and compensate vs cases in whom there was no malpractice accepted behind the claim (Tables 5, 6).

\section{Discussion}

In order to improve the quality of groin hernia surgery it is most important to identify risk factors for adverse outcomes. The present study showed acute surgery, reoperation for recurrence, suture repair and general anaesthesia to be associated with a significantly increased risk for surgical complications leading to damage claims, whereas local anaesthesia reduced the risk. On the other hand surgical technique did not seem to be an independent risk factor (an exception being sutured repair, a technique rarely employed these days). Although not statistically significant, more females than males filed claims. These risk factors are definitely important and must be taken into account in efforts to improve the quality of groin hernia repair.

A subgroup analysis showed that compensated patients did not differ in risk factors compared with the whole group. In compensated patients acute operations and suture repair were significant risk factors but local anaesthesia reduced the risk. The presence of risk factors should be taken into account and minimized in efforts to improve the quality of groin hernia repair.

The strength of this analysis is that data were collected from two existing but not collaborating registers in Sweden; a well-established national insurance company (LÖF) and the Swedish Hernia Register (SHR). The information retrieved from the insurance company database was based on both the patient's claim and their medical records.

The limitations were the relatively small number of claims and nature of a retrospective analysis and sometimes incomplete data characteristic. There was also an imbalance of data from the two systems used. Furthermore, risk factors for claims are influenced by subjective factors and not necessarily related to complications or malpractice. 
Table 2 Claimed injuries to the Swedish National Patient Injury Insurance (LÖF) from 130 patients after operation for inguinal or femoral hernia in 2008 through 2010

\begin{tabular}{lcc}
\hline Injury claimed & Total, $n(\%)$ & Compensated, $n(\%)$ \\
\hline Hematoma or bleeding & $26(20)$ & $19(73)$ \\
Infection & $11(8)$ & $9(82)$ \\
Nerve pain-neuralgia & $24(18)$ & $5(21)$ \\
Urinary problems & $7(5)$ & $7(100)$ \\
Intestinal injury & $7(5)$ & $7(100)$ \\
Testicular injury & $5(4)$ & $5(100)$ \\
Testicular injury + orchidectomy & $15(12)$ & $13(87)$ \\
Spermatic cord injury & $2(2)$ & $0(0)$ \\
Sexual dysfunction & $2(2)$ & $0(0)$ \\
Dental injury & $14(10)$ & $6(43)$ \\
Ugly scar & $2(2)$ & $0(0)$ \\
Miscellaneous & $7(5)$ & $4(57)$ \\
Wrong diagnosis & $6(5)$ & $5(83)$ \\
Not analysed by LÖF & $2(2)$ & $0(0)$ \\
Total & $130(100)$ & $80(60)$ \\
\hline
\end{tabular}

Table 3 Complications after operation of inguinal or femoral hernia according to the Swedish Hernia Register in 48,365 patients in 2008 through 2010

\begin{tabular}{ll}
\hline Type of complication & $n(\%)$ \\
\hline No complication & $44,509(92)$ \\
Bleeding & $1,429(3)$ \\
Infection & $574(1)$ \\
Nerve pain & $264(0,5)$ \\
Urinary retention & $613(1)$ \\
Several complications & $282(0,5)$ \\
Miscellaneous & $694(1)$ \\
Missing & 209 \\
Total & 48,574 \\
\hline
\end{tabular}

There was an inconsistency between the damage claims following hernia repair surgery dealt with by LÖF, and complications registered in the SHR. Almost 50\% of complications leading to a damage claim were not recorded in the SHR confirming that registration of complications is a weakness of the register [2]. But it is also reasonable to assume that other factors, besides complications, play a role in claiming-behaviour that need further investigations and that some patients seek help for postoperative complications from other healthcare facilities not associated with the SHR, such as, general practice. There may also be disagreement between what the doctor and the patient consider as a complication. The present study indicates that there are a substantial number of patients experiencing an adverse event that do not result in a claim. Despite the annual validation process, a tendency to underreport complications to the SHR has been recorded at some units. Miscommunication may be another cause of a claim. Often the patient reports an injury due to inadequate information.
Table 4 Risk factors (Odds Ratio, 95\% confidence interval and $p$ value) for claiming compensation to the Swedish National Patient Injury Insurance after hernia surgery in Sweden in 2008 through 2010

\begin{tabular}{|c|c|c|c|}
\hline & OR & $95 \% \mathrm{CI}$ & $p$ value \\
\hline \multicolumn{4}{|l|}{ Gender } \\
\hline Female vs male & 1.63 & $0.98-2.71$ & 0.06 \\
\hline \multicolumn{4}{|l|}{ Type of admission } \\
\hline Emergency vs elective & 2.03 & $1.14-3.60$ & 0.02 \\
\hline \multicolumn{4}{|l|}{ Anaesthesia } \\
\hline General vs local/regional & 1.95 & $1.22-3.11$ & 0.005 \\
\hline Regional vs general/local & 1.02 & $0.54-1.96$ & 0.94 \\
\hline Local vs general/regional & 0.38 & $0.20-0.70$ & 0.002 \\
\hline \multicolumn{4}{|l|}{ Hernia anatomy } \\
\hline Femoral vs inguinal & 0.77 & $0.25-2.43$ & 0.66 \\
\hline \multicolumn{4}{|l|}{ Type of hernia } \\
\hline Recurrent vs primary & 4.36 & $2.72-6.96$ & 0.001 \\
\hline \multicolumn{4}{|l|}{ Type of repair } \\
\hline Suture vs open mesh/laparoscopic & 2.21 & $1.19-4.10$ & 0.01 \\
\hline Laparoscopic/suture vs open mesh & 1.28 & $0.82-2.00$ & 0.27 \\
\hline Laparoscopic vs open mesh/suture & 0.94 & $0.54-1.63$ & 0.82 \\
\hline
\end{tabular}

Univariate odds ratios based on two by two tables of SHR and Swedish National Patient Injury Insurance (LÖF)

However, the insurance company does not compensate only because of inadequate information concerning potential risks. In this study no claim was considered to be related to miscommunication.

This study indicates that women tend to file claims more often than men. This increased risk $(0.41 \%)$ compared with men $(0.25 \%)$ is difficult to understand. A previous study showed that more women require emergency groin hernia repair and had a significantly higher risk of reoperation for recurrence than men. Furthermore, women are often 
Table 5 Risk factors (Odds Ratio, 95\% confidence interval and $p$ value) for receiving compensation from the Swedish National Patient Injury Insurance after hernia surgery in Sweden in 2008 through 2010

Table 6 Patient characteristics in the claim database from the Swedish National Patient Injury Insurance (LÖF). All operations done between January 1, 2008 and December 31, 2010

\begin{tabular}{llll}
\hline & OR & $95 \%$ CI & $p$ value \\
\hline $\begin{array}{l}\text { Gender } \\
\text { Female vs male }\end{array}$ & 1.54 & $0.80-2.99$ & 0.20 \\
Type of admission & & & \\
$\quad$ Acute vs elective & 2.31 & $1.15-4.63$ & 0.02 \\
Anaesthesia & & & \\
General vs local/regional & 1.51 & $0.87-2.61$ & 0.14 \\
Regional vs general/local & 1.18 & $0.54-2.56$ & 0.68 \\
Local vs general/regional & 0.51 & $0.26-1.03$ & 0.06 \\
Type of repair & & & 0.0114 \\
Open mesh vs laparoscopic/suture & 0.5151 & $0.3082-0.8610$ & 0.2593 \\
Laparoscopic vs open mesh/suture & 1.4271 & $0.7693-2.6475$ & 0.1652 \\
Suture vs open mesh/laparoscopic & 1.5489 & $0.8349-2.8734$ &
\end{tabular}

Univariate odds ratios based on two by two tables of SHR and Swedish National Patient Injury Insurance LÖF)

\begin{tabular}{|c|c|c|c|}
\hline & Non compensated & Compensated & $p$ value* \\
\hline \multicolumn{4}{|l|}{ Gender } \\
\hline Male (\%) & 43 & 70 & \multirow[t]{3}{*}{1.000} \\
\hline Female $(\%)$ & 7 & 10 & \\
\hline Total & 50 & 80 & \\
\hline \multicolumn{4}{|l|}{ Age } \\
\hline \multicolumn{4}{|l|}{ Median, years } \\
\hline \multicolumn{4}{|l|}{ Hernia anatomy } \\
\hline Inguinal (\%) & 49 & 78 & \multirow{3}{*}{1.000} \\
\hline Femoral (\%) & 1 & 2 & \\
\hline Total & 50 & 80 & \\
\hline \multicolumn{4}{|l|}{ Type of hernia } \\
\hline Primary (\%) & 45 & 61 & \multirow[t]{3}{*}{0.083} \\
\hline Recurrent (\%) & 5 & 19 & \\
\hline Total & 50 & 80 & \\
\hline \multicolumn{4}{|l|}{ Type of operation } \\
\hline Elective (\%) & 46 & 71 & \multirow[t]{3}{*}{0.764} \\
\hline Acute $(\%)$ & 4 & 9 & \\
\hline Total & 50 & 80 & \\
\hline \multicolumn{4}{|l|}{ Hernia repair } \\
\hline Open sutured repair (\%) & 2 & 9 & 0.262 \\
\hline Laparoscopic (\%) & 3 & 12 & 0.200 \\
\hline Open mesh repair $(\%)$ & 43 & 57 & \multirow[t]{3}{*}{0.083} \\
\hline Not stated $(\%)$ & 2 & 2 & \\
\hline Total & 50 & 80 & \\
\hline \multicolumn{4}{|l|}{ Type of anaesthesia } \\
\hline General anaesthesia (\%) & 44 & 63 & 0.268 \\
\hline Local $(\%)$ & 1 & 9 & 0.113 \\
\hline Epidural or spinal $(\%)$ & 4 & 7 & 1.000 \\
\hline Not stated (\%) & 1 & 1 & - \\
\hline Total & 50 & 80 & \\
\hline
\end{tabular}

* Chi-square test 
operated by techniques associated with the lowest risk for reoperation in men but had the highest risk in women. That may put women at a higher risk for complications [3]. In a study on damage claims in all types of health care women have been shown to file damage claims more often than men and also receive compensation to a higher extent [4]. This tendency could influence the results found in the present study.

Peri- or postoperative bleeding was reported in $3.0 \%$ (1 429) of all hernia repairs in the SHR.

Only 8 of these led to a damage claim, 5 of which resulted in compensation.

Intestinal complications are rare in groin hernia surgery. In the LÖF material $5 \%$ of claims were due to this complication and all received compensation.

Nineteen per cent of claims to LÖF were due to postoperative pain while pain was reported in less than $1 \%$ in the SHR. Postoperative pain develops sometimes after hernia repair and this was seen in the LÖF material. Pain can be a long-lasting problem for the patient and the overall incidence of moderate to severe chronic pain after groin hernia surgery is around 10-12\% [5-7].

Fifteen per cent of the claims to LÖF dealt with testicular injury and most resulted in orchidectomy. None of these were registered in the SHR. Testicular damage was the result of necrosis caused by vascular complications. These claims were considered as malpractice in all but one case and the claimants were compensated.

Of all claims received by LÖF, $60 \%$ of the patients received compensation. Somewhat more than $50 \%$ of these complications appeared within 30 days post-surgery and should therefore have been eligible for registration in the SHR. Several of the injuries reported were clearly beyond the scope of the SHR. These included dental problems related to anaesthesia $(n=14)$, nerve pain $(n=25)$ and disfiguring scars $(n=2)$ identified by the claimant months or even years after surgery.

Earlier studies have shown that local anaesthesia is associated with advantages compared to general and regional anaesthesia like less complications and early postoperative pain [8]. It is partly consistent with the significant differences in present study in which the complaints, like urinary problems and dental injuries rarely or never occur in connection with local anaesthesia.

Registration of complications is most often a weak point and results of this study underline previous findings that there may be a discrepancy in adverse event rates between the number of damage claims and complications recorded in a structured follow-up system [9]. It has to be underlined that the malpractice claims is a super selective group of individuals who have suffered from a consequence that was not anticipated after a routine surgical procedure. There are, however, strong reasons to believe that the vast majority of serious complications were included in the SHR. In a recently published study in which data from SHR were linked with the National Swedish Patient Register to analyse the severe complications within 30 days of groin hernia surgery it was found that $0.2 \%$ of patients suffered from a severe surgical event within 30 days of groin hernia surgery [10]. Almost all of these complications were registered in SHR. This finding illustrates the need to collect data from a variety of different sources if one is to acquire a complete picture of healthcare outcome [11].

The high rate of compensated injuries $(60 \%)$ can be explained by the fact that LÖF covers all reported injuries if it can be proved that the injury is related to medical care and is considered by the sufferer as malpractice. There are no regulations requiring disciplinary action following a decision by LÖF.

\section{Conclusions}

By linking data between a malpractice insurance company database (LÖF) and a national quality register (the SHR), risk factors associated with damage claims due to complications associated with groin hernia repair were identified. Acute and recurrent surgery, suture repair and general anaesthesia were found to be associated with increased risk for a damage claim whereas local anaesthesia reduced the risk.

Data collected from two different sources identified patients with complications that, in the case of SHR, should, and in the case of LÖF could have been present but were to some extent absent. This underlines the necessity to collect data from different sources if one is to acquire a full picture of healthcare outcome in general and with surgery in particular.

\section{Compliance with ethical standards}

Conflict of interest All authors declare no conflict of interest.

Financial disclosure None of the authors have any conflicts of interest, including relevant financial interests, activities, relationships, and affiliations, to disclose.

Funding/support There was no financial and material support for this work.

Ethical approval The study was approved by the Regional Ethics Committee of Umeå University.

Statement of human and animal rights All procedures performed in studies involving human participants were in accordance with the ethical standards of the institutional and/or national research committee and with the 1964 Helsinki declaration and its later amendments or comparable ethical standards. 
Informed consent Informed consent was obtained from all individual participants registered in SHR and included in the study.

Open Access This article is distributed under the terms of the Creative Commons Attribution-NonCommercial 4.0 International License (http://creativecommons.org/licenses/by-nc/4.0/), which permits any noncommercial use, distribution, and reproduction in any medium, provided you give appropriate credit to the original author(s) and the source, provide a link to the Creative Commons license, and indicate if changes were made.

\section{References}

1. Nilsson E, Haapaniemi. Assessing the quality of hernia repair. Nyhus and Condońs Hernia, Editors Fitzgibbons Jr, Greenburg AG. Fifth ed. Philadelphia: Lippincott Williams \&Wilkins; 2002, pp 567-73

2. Lundström KJ, Sandblom G, Nordin P (2012) Risk factors for complications in groin hernia surgery. A National Register Study. Ann Surg 255(4):784-788

3. Koch A, Edwards A, Haapaniemi S, Nordin P, Kald A (2005) Prospective evaluation of 6895 groin hernia repairs in women. $\mathrm{Br}$ J Surg 92:1553-1558

4. Pukk K, Lundberg J, Penaloza-Pesantes RV, Brommels M, Gaffney FA (2003) Do women simply complain more? National patient injury claims data show gender and age differences. Qual Manag Health Care 12(4):225-231

5. Simons MP, Aufenacker T, Bay-Nielsen M, Bouillot JL, Campanelli G, Conze J, de Lange D, Fortelny R, Heikkinen T, Kingsnorth A, Kukleta J, Morales-Conde S, Nordin P, Schumpelick V, Smedberg S, Smietanski M, Weber G, Miserez M (2009) European Hernia Society guidelines on the treatment of inguinal hernia in adult patients. Hernia 13(4):343-403

6. Aasvang E, Kehlet H (2005) Chronic postoperative pain: the case of inguinalherniorrhaphy. Br J Anaesth 95:69-76

7. Poobalan AS, Bruce J, Smith WC, King PM, Krukowski ZH, Chambers WA (2003) A review of chronic pain after inguinal herniorrhaphy. Clin J Pain 19:48-54

8. Joshi GP, Rawal N, Kehlet H et al (2012) Evidence-based management of postoperative pain in adults undergoing open inguinal hernia surgery. Br J Surg 99(2):168-185. doi:10.1002/bjs.7660

9. Fränneby U, Sandblom G, Nyrén O, Nordin P, Gunnarsson U (2008) Self-reported adverse events after groin hernia repair, a study based on a national register. Value Health 11:927-932

10. Nilsson H, Angerås U, Sandblom G, Nordin P (2016) Serious adverse events within 30 days of groin hernia surgery. Hernia 20(3):377-385

11. Brown C, Hofer T, Johal A, Nicholl J, Franklin BD, Lilford RJ (2008) Developing research and practice. An epistemology of patient safety research: a framework for study design and interpretation. Part 3. End points and measurements. Qual Saf Health Care 17(3):170-177 